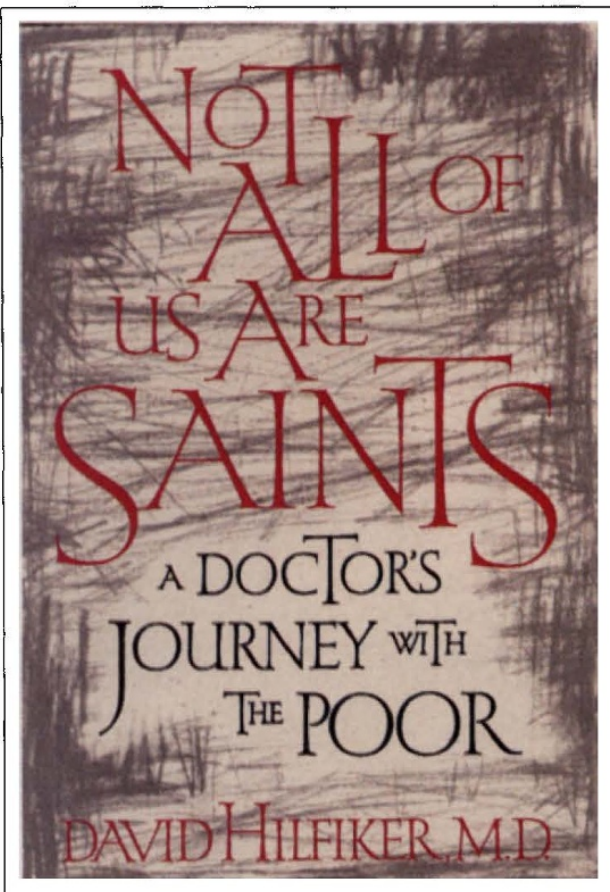

\section{Not All of Us Are Saints}

\author{
by David Hilfiker \\ Farrar, Strauss and Giroux $\$ \mathbf{2 0 . 0 0}$
}

\section{RUTH S. HANFT}

Few if any of us are saints. Some choose to work at maximum stress and frustration, sometimes on a minimum income, providing health care to the homeless, perhaps the most deprived citizens among us. David Hilfiker alternates the stories of homeless, frequently substance-abusing, patients with his own spiritual and religious motivations and conflicts. $\mathrm{He}$ is a sensitive, caring, conflicted physician who traveled from rural practice burnout to inner-city burnout.

And yet, implicit in the current debate about health care in the United States and the desire to increase the number of physicians in primary care, general practice, is the idea that this proposed shift to primary care will benefit the homeless and the poor. We know that this population consumes a significant portion of the healthcare dollar because they so often come into the medical system only when their ailments have become serious - and, consequently, more expensive. By increasing the number of physicians in primary care we, theoretically, will reduce this burden. The poor among us will get care earlier. Costs will decrease and social justice might even be served.

Hilfiker's poignant book about his life as a well-educated white physician, living and practicing primary care among the poor of Washington, DC, tells a different, truer tale.

The patients' stories and the bureaucratic barriers preventing access to all forms of care will be very familiar to those who have worked with disadvantaged populations and in the inner cities. The District of Columbia around the US capitol, the setting for this book, perhaps represents the ex-

[I was] not prepared for the hostility, the seeming ingratitude, the noncompliance, the irrationality that is so much a part of inner-city reality...

treme example of a lack of collaboration between public and private agencies and a subsequent and collective failure to meet the educational, housing, health and social needs of its population. It also offers stark examples of the fiefdoms that have developed around categorical programs designed to meet specific needs of a particular population and of the desensitizing of those public and private employees who dedicate part of their lives to working on seemingly intractable social problems.

Hilfiker's book is written from the individual's perspective of the personal goals and frustrations of a "worker in the fields of the Lord." The book would have benefitted from consideration of the broader perspective of the disorganization of public and private social policy that has led to a multiplicity of public and private programs, each one addressing problems in a narrow and fragmented manner, making it virtually impossible for providers and beneficiaries to navigate the treacherous waters of complex eligibility rules and the like.

Perhaps the most important contribution this book makes to the arena of community medicine comes in the scattered comments on medicine and the care of the disadvantaged. Hilfiker makes a number of important observations that should be taken seriously particularly by the medical education community: "The book is less about medicine than class ... than race ... than culture. " Hilfiker reports that he was "not prepared for the hostility, the seeming ingratitude, the noncompliance, the irrationality that is so much a part of innercity reality" and that he "know[s] of few medical schools that prepare future physicians for the complex social, cultural, linguistic, educational barriers to providing care for inner-city low income populations, either in the didactic or clinical curriculum."

Of interest are those sections of the book devoted to the author's personal spiritual, religious and ethical journey, which reflect the usual inarticulate conflicts so common to those who work on programs for the very poor. What makes the author's account of such conflicts stand out above the norm may be his stronger religious orientation when compared to more secularly oriented colleagues.

A major issue he struggled with was the impact, on members of his family, of the clients he lived in such close proximity to. The author's decision to live in the same building and later communally with clients of the Homeless Respite Center was brave and created a remarkable juxtaposition. This is reflected in long passages on guilt and distributive justice. Hilfiker feels guilt that he responds differently to either middle class or homeless patients, and at the cultural chasm between himself and the low-income patients. He differently is torn by the decision to send his children to a prestigious private school, when his patients' children have no such option. And when he finds himself exhausted and no longer able to offer his best, he has the opportunity to retreat and recover in Finland: an option not open to most salaried middleclass citizens, never mind his luckless patients. Yet, to impress on his children the difference between real needs and luxuries he at first requires his daughter to pay for part of her own braces.

For those familiar with the health and social problems of the poor and inner-city residents, the stories of the patients are very familiar and for those who work in programs for the disadvantaged, the personal conflicts recounted here may well be similar to their own, although Hilfiker's are almost certainly grounded in a deeper evangelical Christianity and probably better articulated. To those whom society has granted great professional and economic status, this book, and ones like it, should be required as part of medical and continuing education.

Professor of Health Services Management The George Washington University Washington, $D C$ 